\title{
A GIS-based Decision-Making Support System for Wind Power Plant Site Selection, Case Study for Saskatchewan
}

\author{
L. R. Liu ${ }^{1,2}$, G. H. Huang ${ }^{2,3 *}$, B. Baetz ${ }^{4}$, and K. Turchenek ${ }^{5}$ \\ ${ }^{1}$ Stockholm Environment Institute, University of York, Wentworth Way, York YO10 5NG, UK \\ ${ }^{2}$ Institute for Energy, Environment and Sustainability Research, University of Regina, Regina, Saskatchewan S4S OA2, Canada \\ ${ }^{3}$ State Key Joint Laboratory of Environmental Simulation and Pollution Control, China-Canada Center for Energy, Environment and Ecology \\ Research, UR-BNU, School of Environment, Beijing Normal University, Beijing 100875, China. \\ ${ }^{4}$ Department of Civil Engineering, McMaster University, Hamilton, Ontario L8S 4L7, Canada \\ ${ }^{5}$ Ministry of Agriculture, Government of Saskatchewan, 3085 Albert Street, Regina, Saskatchewan S4S OB1, Canada
}

Received 17 October 2019; revised 13 November 2019; accepted 12 December 2019; published online 31 December 2019

\begin{abstract}
The increasing developments of wind power plants occur in many countries, which are used to mitigate the adverse effects of fossil fuels on the environment. In consideration of negative impacts, wind energy should be systematically analyzed in order to optimize the plans of governments and developers. A decision-making support system for wind power plant site selection was developed by using geographical information system in this study. The environmental, economic, and technical factors are invoked to generate the methodology. By comparing the overall performance index from the results, the best locations for wind power plants can be selected. The methodology was applied to the case study of Saskatchewan, where the development of wind power plant could be considered urgent. The results demonstrate that Saskatchewan has great potential for wind power energy development and southwest Saskatchewan is the most favorable area.
\end{abstract}

Keywords: GIS; Wind energy, site selection, decision-making support

\section{Introduction}

Global warming and climate change are currently two of the largest challenges facing the world's population (Cai et al., 2007; Li et al., 2007; Aguilera et al., 2018; Liu et al., 2018b). It is found that the emissions of Greenhouse Gas (GHG) are the main reason resulting in global warming, which cause huge attention and force many countries and constitutions to be concentrated on a method to reduce the emissions (Du et al., 2018; Liu et al., 2019; Yu et al., 2019). Renewable energy, especially wind power energy, plays a key role in reducing the GHG emissions. Wind energy is considered to be a clean, renewable energy due to its few emissions, both in construction and operation periods (Global Wind Energy Council, 2018; Kozlova and Yeomans, 2019; Li et al., 2018). Thus, it is necessary to develop wind energy to mitigate GHG emissions.

In Canada, wind industry's performance continued a trend of strong and stable growth. There are 12,816 MW total installed wind energy capacity in Canada till 2018 (Canadian Wind Energy Association, 2018). However, the distribution of the wind power plants is unbalanced, with the majority of wind power plants located in Ontario and Quebec (Canadian Wind

* Corresponding author. Tel: +1 3065854095; fax: +13063373205.

E-mail address: huang@iseis.org (G. H. Huang).

ISSN: 2663-6859 print/2663-6867 online

(C) 2019 ISEIS All rights reserved. doi:10.3808/jeil.201900022.
Energy Association, 2018). Due to the energy sources and economic structure, western Canadian provinces, including the Province of Saskatchewan, emit considerable GHG emissions (Liu et al., 2018a). But the wind power plants are limited in Saskatchewan. Considering the GHG mitigation targets that proposed in Paris Agreement (United Nations Framework Convention on Climate Change, 2015), it is necessary to develop wind energy in Saskatchewan. Comprehensive analysis is desired in order to maintain a win-win situation combining both economic and environmental impacts.

Besides the limited wind power resources, there are some other factors that restricted the development of wind power plants (Li et al., 2018; Liu et al., 2018c). In contrast to fossil fuels, wind power plants do not emit GHG to the atmosphere (Chen et al., 2018; Ren et al., 2018). But wind power plants have some unavoidably negative impacts on society and ecology, for example, noise, visual impacts and other negative impacts. A listening test was performed to investigate the relationship between human annoyance and the amplitude modulation of wind turbine noise. The results indicated that the equivalent sound level and the amplitude modulation of wind turbine noise both significantly contribute to noise annoyance (Lee et al., 2011). To investigate the characteristics of noise propagation from wind turbine, Son et al., adopted the integrated numerical methods based on Ray theory. The noise level on the ground was predicted including the effects of air absorption, ground re- 
flection and diffraction (Son et al., 2010). In terms of visual impact, different assessment methods, such as the Quechee Test, Multicriteria Analysis and the Spanish method, were developed and applied in different cases (Leung and Yang, 2012). For instance, an application of the Contingent Valuation Method (CVM) for valuing the landscape externalities associated with the large-scale exploitation of wind power at the local level was conducted in South Evia, Greece. The results showed that 57\% of the households were not willing to contribute financially in order to implement interventions to mitigate the visual impact of wind farms (Mirasgedis et al., 2014). Another negative impact of wind power plant is the danger to birds, since wind power plant may be built in birds' habitats. A generalized impact assessment with respect to temporal and spatial extent of the pressure, effect within each ecosystem component, and level of certainty was proposed to evaluate the effects of offshore wind power plants on marine wildlife, which indicated that potential impacts on marine life should be carefully considered in marine spatial planning (Bergström et al., 2014).

Due to the above potential negative impacts that may be caused by wind power plant, the site selection for wind power plant is crucial for its future development (Guo et al., 2018). Since 2000, many researchers conducted studies about wind power plant site selection all over the world. In 2010, Hoesen and Letendre described a model to support rural community energy planning. In this study, a wind class dataset and landscape restrictions were used to calculate wind potential in Poultney, Vermont (Van Hoesen and Letendre, 2010). Haaren and Fthenakis used spatial multi-criteria analysis (SMCA) to select a wind farm site for New York State on the basis of a spatial cost-revenue optimization. This method can assist developers to plan, especially for large geographic areas (Van Haaren and Fthenakis, 2011). Based on physical factors, the wind resource distribution and the technical specifications, Grassi et al. (2012) estimated the average Annual Energy Production (AEP) to support energy planners and wind farm developers. The proposed model was applied to the state of Iowa and results showed that average AEP of Iowa is $914 \mathrm{TWh}$ and the potential total installed capacity is $302 \mathrm{GW}$. A combination of analytic network process (ANP) and decision-making trial and evaluation laboratory (DEMATEL) methods in geographyical information system (GIS) environment was developed to assess the possibility of establishing wind farms, where ANPDEMATEL was used to determine the weight of influence factors. A case study of Ardabil province in northwestern Iran further illustrated the applicability of the proposed model (Azizi et al., 2014). Latinopoulos and Kechagia proposed and implemented an integrated evaluation framework for selecting the most appropriate sites for wind-farm development projects through the combination of GIS and spatial multi-criteria decision analysis. The case study of Greece was conducted to support the potential role of planners in designating areas for wind farm development (Latinopoulos and Kechagia, 2015).

To improve the robustness of the site selection for wind power plant, different methods and models were developed and adopted. For example, Sliz-Szkliniarz and Vogt developed an approach to support the decision-making process connected with site selection for wind energy projects, which first identified available locations and then calculated the technical potential and economic viability (Sliz-Szkliniarz and Vogt, 2011). A spatial decision support system that integrates environmental and economic criteria and builds a hierarchy for wind power plant siting using weighted linear combination (WLC) techniques and GIS functionality was developed in order to promote group decision making that can involve participants with different interests in the development of decision alternative (Gorsevski et al., 2013). Fuzzy sets have been used to represent the environmental objectives and wind energy potential (Aydin et al., 2010). The authors then used an Ordered Weighted Averaging (OWA) operator as the multi-criteria decision making (MCDM) tool to calculate the overall satisfaction degree.

However, a review of the literature indicates that the criteria used in different studies are conflicting. Some studies classified the criteria to five types, including planning, ecological, physical, economic factors and bird impact. Some studies only conducted technical and economical assessment to study the wind potential. There are limited comprehensive studies that taken all of the factors into consideration. Moreover, there have been few GIS siting studies published for wind farms in Saskatchewan, where the development of wind power plant could be considered urgent.

Therefore, the objective of this paper is to develop a GISbased decision-making support system (GDSS) for wind power plant site selection. An overall performance index (OPI) is proposed to evaluate the potential sites comprehensively and provide the information to decision-makers intuitively. Saskatchewan is analyzed as a reference case in order to verify the approach. In this paper, the criteria are classified into three major types by means of the proposed approach, including technical, environmental and economic aspects. The potential wind power plant sites are selected to further support the future development.

\section{Methodology}

\subsection{The GIS-Based Decision-Making Support System}

A GIS-based decision-making support system (GDSS) for wind power plant site selection is developed by integrating GIS and decision-making analysis. The framework of the proposed system for wind power plant site selection is shown in Figure 1. It can be seen that the first step is to identify the criteria, which contains technical, environmental and economic aspects. Then the data are processed in GIS to get the potential areas. Lastly, an overall performance index (OPI) is proposed to evaluate the potential sites comprehensively. The OPI provides the direct information to the decision makers and IS beneficial for the comparisons of the potential areas. The methodology is explained in detail in this section as follows. Specially, wind speed data, which is one important factor that affect the site selection for wind power plant, does not match the resolution of other data. By georeferencing the wind speed data, they are presented in ArcMap and subsequently the wind speed in every point is obtained. 


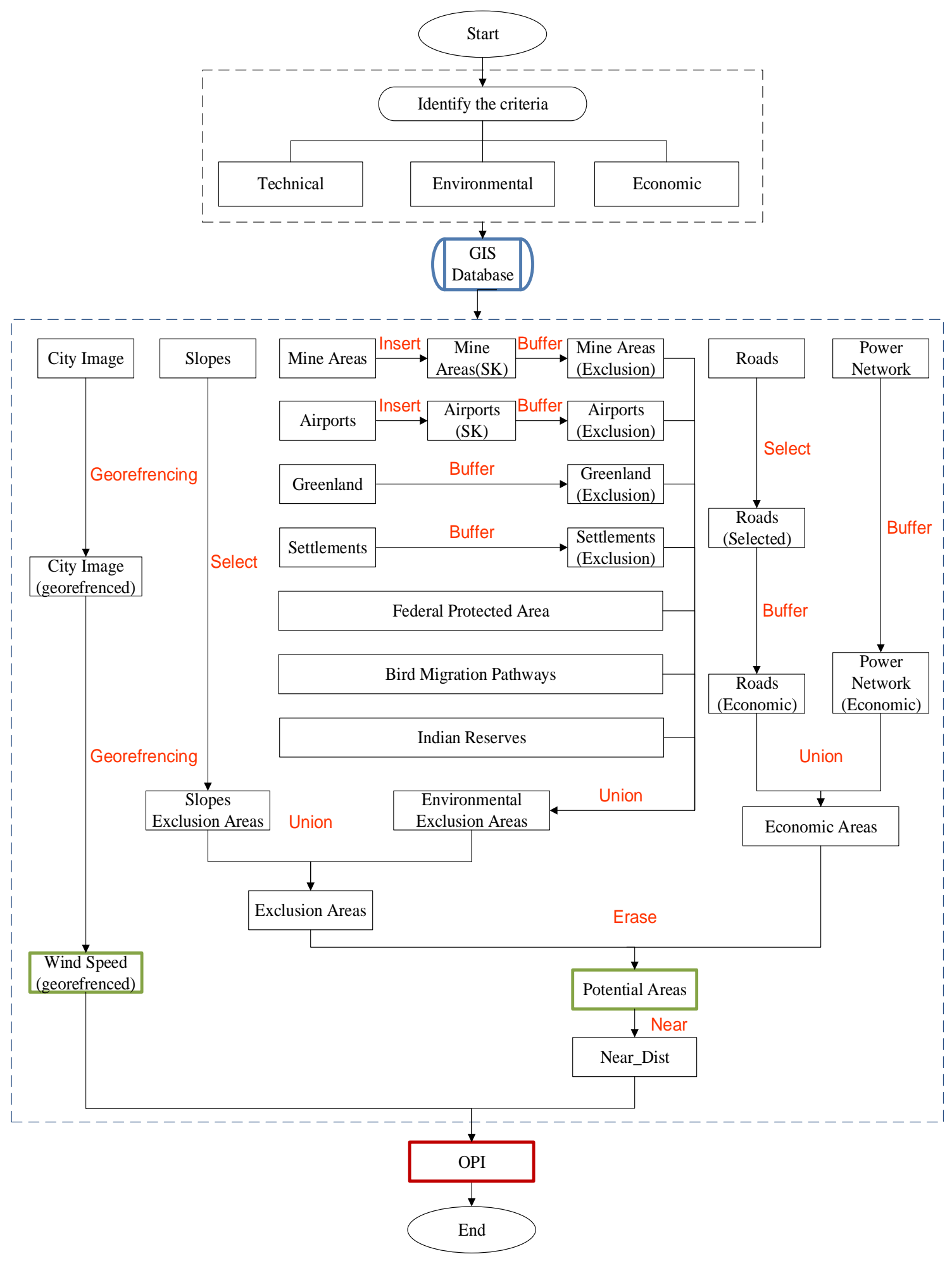

Figure 1. The methodology of the study.

The final GDSS contains three major sections, including the potential areas map, the wind speed map, and the OPI values. When using the developed GDSS, the potential areas map and wind speed map will be generated first. After that, if there are several possible wind power plant sites, the GDSS will compare them in three aspects, including environmental, economic, and technical aspects. The results will be provided through the OPI values. The decision-makers can then make her decision 
by comparing OPI values to select the general best location, or by comparing the separated performance index to select the best location in the aspect she concerned mostly.

\subsection{Identify the Criteria}

There are seven types of criteria that were used in previous studies, including environmental, economic, ecological, physical, plan, policy and technical aspects. After comprehensive summaries and analyses, the criteria used in this paper have been classified into three types, which are environmental, economic and technical aspects. The environmental criteria are chosen to protect the environment. The wind turbines should be away from green land, water bodies and other environmentally sensitive classes. For the economic criteria, roads and power networks are needed during the construction and operation periods of the wind power plants. The costs of road construction and grid connection can be $3 \sim 15 \%$ of the total cost. The technical data criteria wind speed and slope, which are two basic requirements for the site of wind power plants.

There are many potential areas under the condition that few wind power plants built in Saskatchewan currently. Furthermore, high standards should be chosen to select the most favorable locations. The criteria were chosen from previous studies since there are no laws and regulations of site selection for the wind power plants in Saskatchewan. The criteria used in this paper are listed in Table 1.

\subsection{Overall Performance Index}

As a decision-making support system, it is supposed to provide people with direct information. If there are several possible options, a specific number is needed to assist the decision maker to compare the options. The last section is to calculate the OPI, which can represent the overall quality with three aspects.

To calculate the OPI, the distances from the possible locations to the nearest roads and power networks should be obtained first. The geoprocessing tool "near" can solve this problem. After adding the possible locations in ArcMap, the possible locations layer is used as the in_feature and the roads and power network layers are used as the near_feature. The search_radius should be the distances in Table 1. Then, the nearest distances will be added to the attribute table of the possible locations. tions:

Next step is calculating the OPI using the following equa-

$$
\begin{aligned}
& O P I=C_{E V} \times C_{E C} \times C_{T E} \\
& C_{E C}=\frac{1}{D_{R} \times D_{P}} \\
& C_{T E}=\frac{W S}{S T}
\end{aligned}
$$

where $C_{E V}$ is the performance index in environmental aspect and $C_{E V}$ is equal to 1 because the criteria used in this paper can satisfy all the environmental requirements; $C_{E C}$ is the performance index in economic aspect; $D_{R}$ represents the distances between the possible locations and the nearest roads; $D_{P}$ represents the distances between the possible locations and the nearest power networks; $C_{T E}$ is the performance index in technical aspect; $W S$ represents the wind speed; $S T$ represents the slope.

\subsection{Data Processing}

According to the identified criteria, the data used in this study is collected and processed. To be specific, the data used in this paper are listed in Table 2 and the data dictionary is shown in Appendix A. Beside the listed data, other data is used directly, such as federal protected area, bird migration pathways and so on.

After the data collection, criteria are still needed before data processing in GIS. In the website of Canadian Wind Energy Atlas, lots of information can be downloaded, such as wind speed, rivers and so on. In this section, these images are imported to GIS and formed the wind speed map.

To show the images in ArcMap, spatial references should be added by using "georeferencing". When using georeferencing, three control points are needed for each image. The images showing the cities were downloaded firstly. Then, these images were georeferenced by using the cities' locations as the control points. After that, the wind speed images can be georeferenced using the corner of the images as the control points.

\section{Results and Discussions}

\subsection{The Potential Areas Identification}

The potential areas which satisfied both environmental and economic criteria are identified through the proposed model. To be specific, the areas that satisfied the environmental criteria and the areas that satisfied the economic criteria are identified separately.

Firstly, the environmental criteria are used to find out the environmental exclusion areas. For mine areas and airports, using "insert" to overlay these two layers with the province boundary layer and get the mine areas and airports in Saskatchewan. Then, buffer the four layers, including mine areas, airports, greenland, and settlements, to get the exclusion layers separately. The buffer distances are the distance listed in Table 1. It can be seen that the buffer distance for airports are the largest, which further illustrates the potential impacts to airports caused by the wind power plant. In contrast, the buffer distance to mine areas is the smallest. For the other environmental criteria, the areas are regulated to be excluded when choosing wind power plants. Thus, the federal protected areas, bird migration pathways and Indian reserves layers are used directly. With the seven exclusion layers obtained through the above environmental criteria, the potential areas that satisfied all the environmental criteria can be obtained by using "union", as shown in Figure 2. It is illustrated that there are more exclusion areas in the south of Saskatchewan, since there are more infrastructures. The exclusion areas in the north of Sas- 
Table 1. The Identified Criteria

\begin{tabular}{llll}
\hline Objective & Criteria & Distance & Reference \\
\hline Environmental & Green Land & $450 \mathrm{~m}$ & Sliz-Szkliniarz and Vogt, 2011 \\
& Mine Areas & $100 \mathrm{~m}$ & Sliz-Szkliniarz and Vogt, 2011 \\
& Settlements & $2000 \mathrm{~m}$ & Baban and Parry, 2001; Nguyen, 2007 \\
& Airports & $2500 \mathrm{~m}$ & Voivontas, et al., 1998; Nguyen, 2007 \\
Economic & Roads & $100 \mathrm{~m} \sim 16000 \mathrm{~m}$ & Sliz-Szkliniarz and Vogt, 2011; Van Haaren and Fthenakis, 2011 \\
& Power Network & $10000 \mathrm{~m}$ & Baban and Parry, 2001 \\
Technical & Wind Speed & $5 \mathrm{~m} / \mathrm{s}$ & Baban and Parry, 2001 \\
& Slope & $10 \%$ & Baban and Parry, 2001 \\
\hline
\end{tabular}

katchewan are relatively larger than the exclusion areas in the south of Saskatchewan, which is caused by the bigger area of the lakes.

Secondly, exclusion areas due to slopes are confirmed. In this step, "select" function is used to find out the areas whose slopes are over $10 \%$ and export the map. The exclusion areas by using slopes are shown in Figure 3. It is demonstrated that the slopes in the south of Saskatchewan are more variable than the north of the Saskatchewan. As a result, the majority of the exclusion areas due to slopes are located in the south of Saskatchewan.

\section{Environmental Exclusion Areas}

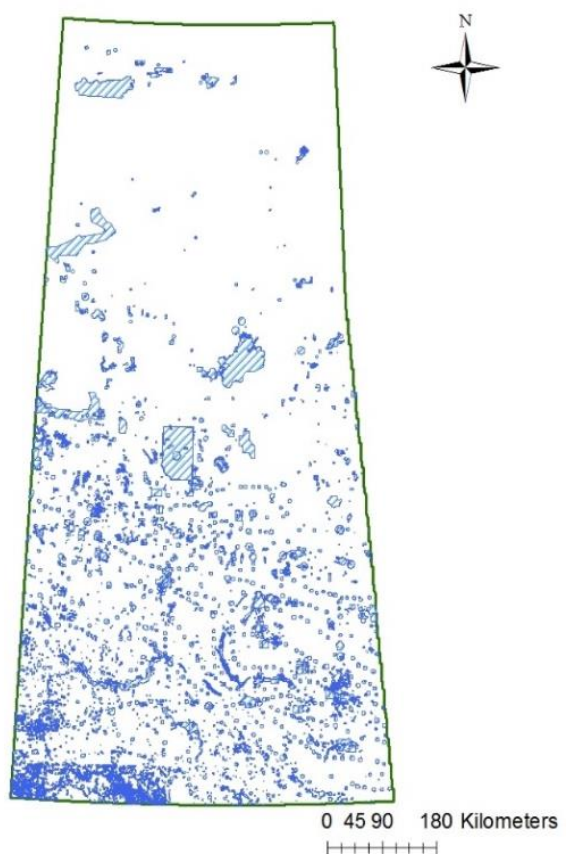

Figure 2. The environmental exclusion areas map.

Following that, the final exclusion areas are defined by using "union" to overlay the environmental exclusion layer and the exclusion layer due to slopes. As shown in Figure 4, there are lots of areas are excluded in the Province of Saskatchewan. When comparing the north and south parts of Saskatchewan, it can be seen that there are more suitable areas in the north of Saskatchewan. In the south of the Province of Saskatchewan, there still are available areas to develop wind power plants, since the wind power plants occupies limited areas and it's should be located close to the electricity demand areas.

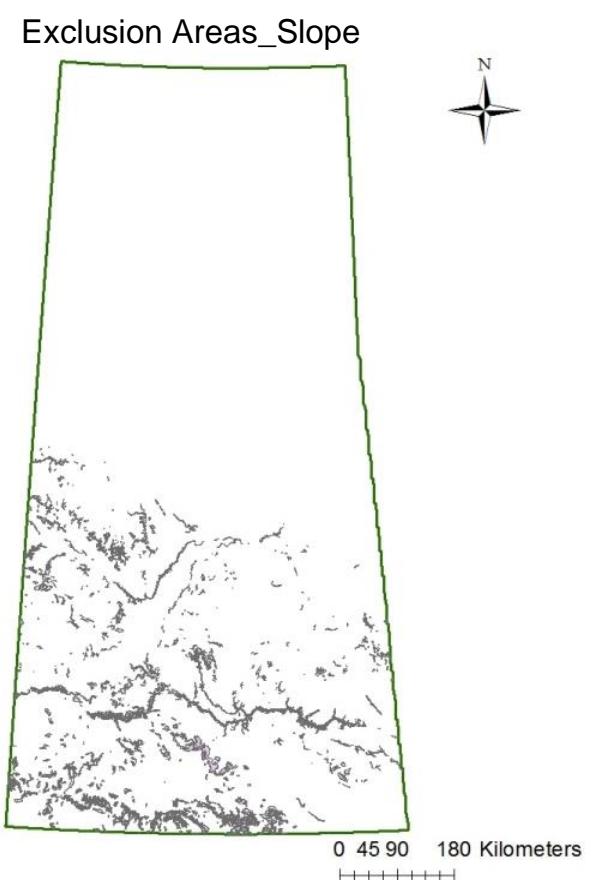

Figure 3. The exclusion areas map due to slopes.

From the economic perspective, roads and power networks are used to obtain the economic areas. When constructing the wind power plants, the roads must be wide and hard enough to support the transportation. The roads layer must be selected initially and leave the roads which satisfy the requirements. After selecting the roads based on its width attribute, the selected roads layer and the power network layer should also be buffered using the regulated distances. Then, by using "union", the two economic layers are overlaid. The final economic areas layer is shown in Figure 5. The obtained economic areas are concentrated in the south of the Province of Saskatchewan, due to the well-developed road and power networks. This result is also related with the entire economic conditions of the study area. Most of the residents are lived in the south of the province, while only limited communities are lived in the north of the province. With more residents, the road, power network, and other utility infrastructures are developed faster than the north communities. 


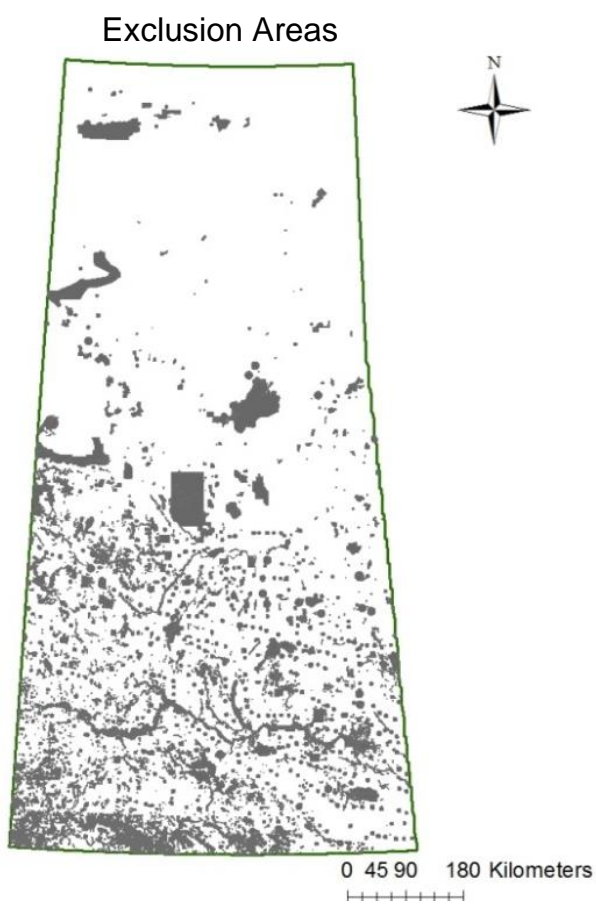

Figure 4. The final exclusion areas map.

\section{Economic Areas}

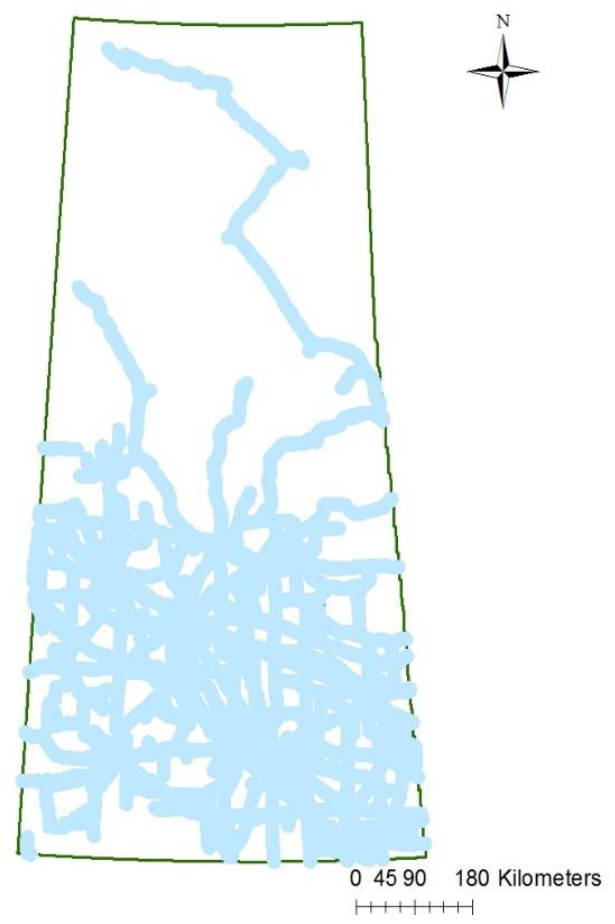

Figure 5. The economic areas map.

Lastly, the potential areas are confirmed. In this step, the "erase" tool is used to overlay the economic areas layer and the exclusion areas layer. The economic areas layer is the input feature and the exclusion areas layer is the erase feature. The potential areas map is shown in Figure 6.

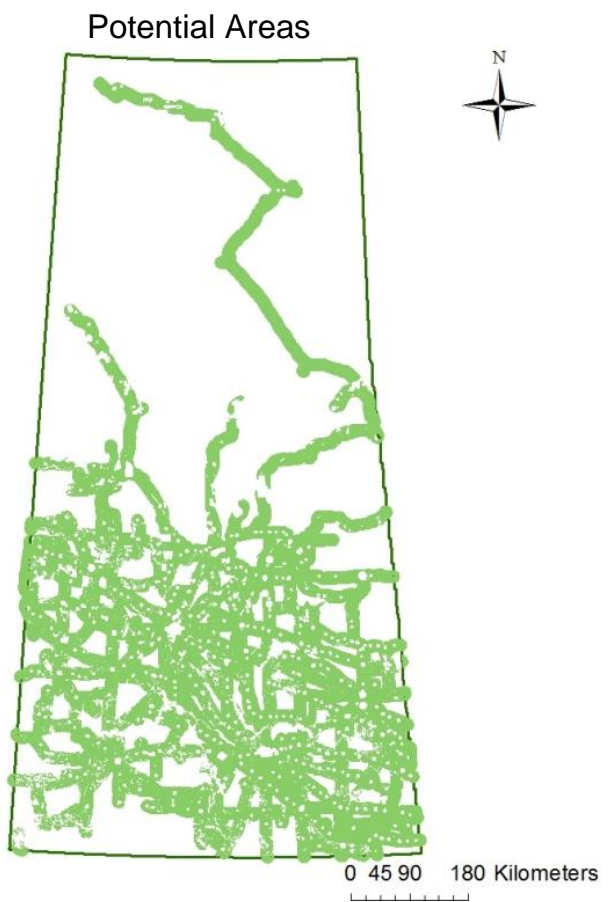

Figure 6. The potential areas map.

\subsection{The Overall Performance}

In this section, several possible locations for wind power plants are proposed according to the actual situation in the case study. After that, the wind speed data, economic data, and environmental related data are calculated based on the proposed model. Finally, the OPI of the possible locations for wind power plants are obtained, which will be helpful for the related decision-making.

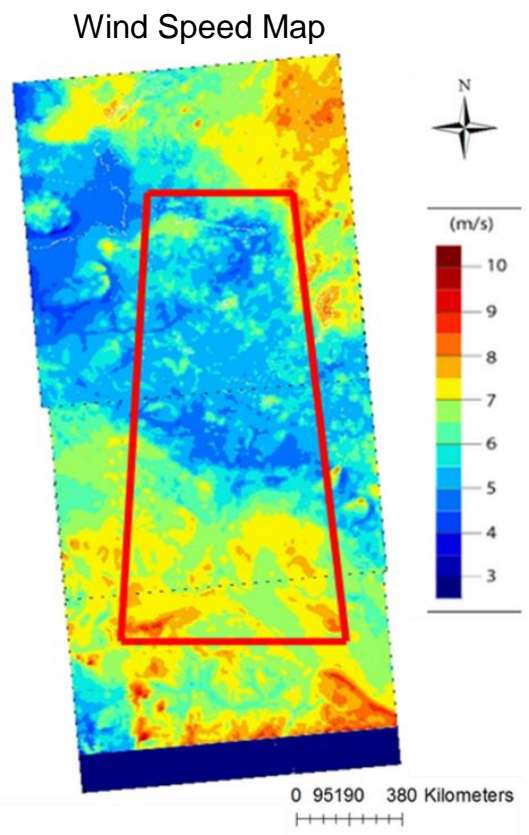

Figure 7. The wind speed map. 
Table 2. The Data Used in This Paper

\begin{tabular}{lll}
\hline Data & Use & Source \\
\hline Provincial Boundary & Base Map & ESRI Press \\
Green Land & Get environmental layer & ESRI Press \\
Water Bodies & & GeoSaskPre-packaged Data Gallery \\
Mine Areas & & ESRI Press \\
Federal Protected Areas & & ESRI Press \\
Bird Migration Pathways & & SRC Publication No. 13230-1C12 \\
Indian Reserves & & ESRI Press \\
Settlements & & ESRI Press \\
Airports & Get economic layer & ESRI Press \\
Roads & & ESRI Press \\
Power Network & Saskatchewan Power Corporation \\
Wind Speed & Get technical layer & Environment Canada (RPN) \\
Slope & & ESRI Press \\
\hline
\end{tabular}

Table 3. The Calculation Results

\begin{tabular}{llllll}
\hline Possible Locations & Wind Speed $(\mathrm{m} / \mathrm{s})$ & Slopes & $\mathrm{D}_{\mathrm{R}}(\mathrm{m})$ & $\mathrm{DP}(\mathrm{m})$ & OPI \\
\hline 6 & 6.8 & 3 & 4215 & 16021 & $3.357 \mathrm{e}^{-8}$ \\
8 & 7.1 & 1 & 14012 & 18200 & $2.784 \mathrm{e}^{-8}$ \\
10 & 7.7 & 3 & 16120 & 9424 & $1.690 \mathrm{e}^{-8}$ \\
\hline
\end{tabular}

The wind speed data in this paper are colourful images and different color represents different wind speed, as shown in Figure 7. There are three possible locations for wind power plants as shown in Figure 8. The three blue points in Figure 8 are location 6 , location 8 , and location 10 . The decision maker aims to choose one location in consideration of the overall performance index.

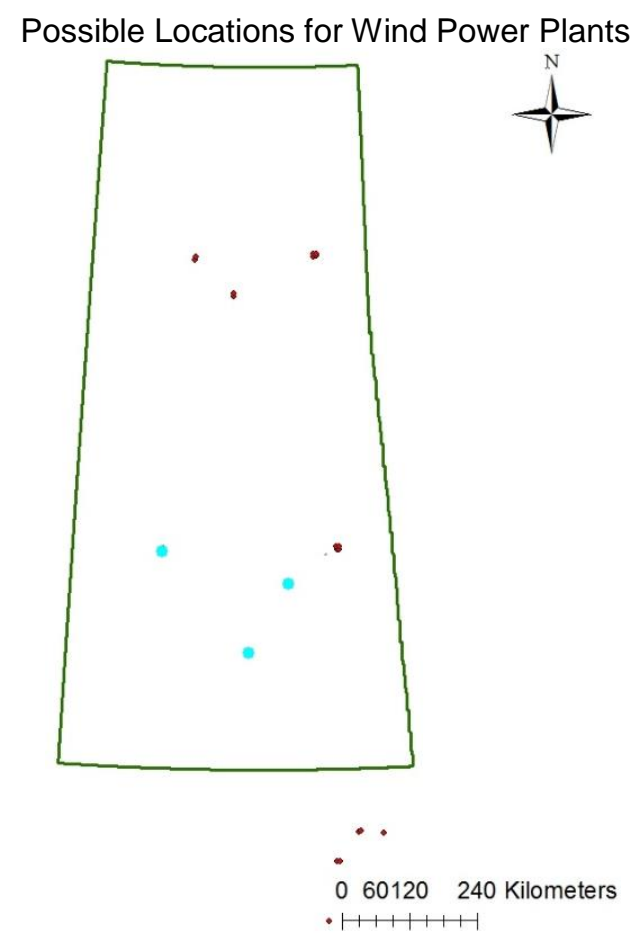

Figure 8. The possible locations for WPPs.
Through the wind speed map, the wind speed of the three locations can be found. Also, the slopes of them can be acquired through the slopes layer. The annual mean wind speeds and slopes of the three locations are listed in Table 3. Similarly, the distance from the possible locations to the nearest roads and power networks are confirmed using "near". The results are also shown in Table 3.

Finally, the OPI of the three possible locations can be calculated using formula (1). The results are listed in Table 3. From the calculation results, we can see that the possible location 6 is the best location for wind power plants in the Province of Saskatchewan. The location 8 ranks at the second among the three possible locations, while the location 10 is the lowest and the differences among location 10 is relatively larger than the differences between location 6 and location 8. Therefore, it is recommended that the wind power plants should be first built in location 6.

\section{Conclusions}

In this paper, GIS-based decision-making support system for wind power plant site selection is developed by integrating GIS and decision-making analysis, which contains the impacts of environmental, economic, and technical aspects. This method is not only useful for comparing the overall performance of potential areas for WPPs, but also capable of choosing locations when considering one specific aspect. What's more, the criteria used in this study can satisfy all the environmental requirements. Thus, the future WPPs can help to solve the global warming and climate change problems without causing other problems.

From the wind speed map and the potential areas map, Saskatchewan has a strong potential to develop wind power 
energy, especially the southwest of the province. However, there are little related laws and regulations in Saskatchewan have been found during the research period. Before developing wind power energy, the government should publish related laws and regulations to guide and protect the wind power industry.

This approach can be further expanded to perform a more comprehensive analysis with more accurate information. The wind speed data used is one of the limitations of this study. If the information is provided as raster data, this method can calculate the OPI of all the possible areas. Then the results can help the government and developers to plan the wind energy development in Saskatchewan. What's more, other data about the wind resources will improve the calculation results, such as wind direction, wind density and so on.

Acknowledgements. This research was supported by the National Key Research and Development Plan (2016YFA0601502).

\section{References}

Aguilera, R., Sabater, S., and Marcé, R. (2018). A methodological framework for characterizing the spatiotemporal variability of river water-quality patterns using dynamic factor analysis. Journal of Environmental Informatics, 31(2), 97-110. https://doi.org/10.3808/ jei.201600333

Aydin, N.Y., Kentel, E., and Duzgun, S. (2010). GIS-based environmental assessment of wind energy systems for spatial planning: A case study from Western Turkey. Renewable and Sustainable Energy Reviews, 14(1), 364-373. https://doi.org/10.1016/j.rser.2009. 07.023

Azizi, A., Malekmohammadi, B., Jafari, H.R., Nasiri, H., and Parsa, V.A. (2014). Land suitability assessment for wind power plant site selection using ANP-DEMATEL in a GIS environment: case study of Ardabil province, Iran. Environmental Monitoring and Assessment, 186(10), 6695-6709. https://doi.org/10.1007/s10661-014-388 3-6

Baban, S.M.J. and Parry, T. (2001). Developing and applying a GISassisted approach to locating wind farms in the UK. Renewable Energy, 24(1), 59-71. https://doi.org/10.1016/S0960-1481(00)0016 9-5

Bergström, L., Kautsky, L., Malm, T., Rosenberg, R., Wahlberg, M., Capetillo, N.A., and Wilhelmsson, D. (2014). Effects of offshore wind farms on marine wildlife-a generalized impact assessment. Environmental Research Letters, 9(3), 34012. https://doi.org/10. 1088/1748-9326/9/3/034012

Cai, Y.P, Huang, G.H., Nie, X.H., Li, Y.P., and Tan, Q. (2007). Municipal solid waste management under uncertainty: a mixed interval parameter fuzzy-stochastic robust programming approach. Environmental Engineering Science, 24(3), 338-352. https://doi.org/10.10 89/ees.2005.0140

Canadian Wind Energy Association. (2018). Installed Capacity. Retrieved from https://canwea.ca/wind-energy/installed-capacity/

Chen, J.S., Chen, W.G., Li, J., and Sun, P. (2018). A generalized model for wind turbine faulty condition detection using combination prediction approach and information entropy. Journal of Environmental Informatics, 32(1), 14-24. https://doi.org/10.3808/jei.201800393

Du, W.J., Chen, X., and Wang, H.F. (2018). PLL performance evaluation considering power system dynamics for grid connection of renewable power generation. Journal of Environmental Informatics, 32(1), 55-62. https://doi.org/10.3808/jei.201800396

Global Wind Energy Council. (2018). Global Status of Wind Power.
Retrieved from https://gwec.net/global-figures/wind-energy-global -status/

Gorsevski, P.V, Cathcart, S.C., Mirzaei, G., Jamali, M.M., Ye, X., and Gomezdelcampo, E. (2013). A group-based spatial decision support system for wind farm site selection in Northwest Ohio. Energy Policy, 55, 374-385. https://doi.org/10.1016/j.enpol.2012. 12.013

Guo, Y., Wang, Q., Zhang, D., Yu, D., and Yu, J. (2018). A stochasticprocess-based method for assessing frequency regulation ability of power systems with wind power fluctuations. Journal of Environmental Informatics, 32(1), 45-54. https://doi.org/10.3808/jei.2018 00394

Kozlova, M. and Yeomans, J.S. (2019). Multi-variable simulation decomposition in environmental planning: An application to carbon capture and storage. Journal of Environmental Informatics Letters, 1(1), 20-26. https://doi.org/10.3808/jeil.201900003

Latinopoulos, D. and Kechagia, K. (2015). A GIS-based multi- criteria evaluation for wind farm site selection. A regional scale application in Greece. Renewable Energy, 78, 550-560. https://doi.org/10.1016 /j.renene.2015.01.041

Lee, S., Kim, K., Choi, W., and Lee, S. (2011). Annoyance caused by amplitude modulation of wind turbine noise. Noise Control Engineering Journal, 59(1), 38-46. https://doi.org/10.3397/1.3531797

Leung, D.Y.C. and Yang, Y. (2012). Wind energy development and its environmental impact: A review. Renewable and Sustainable Energy Reviews, 16(1), 1031-1039. https://doi.org/10.1016/j.rser. 2011.09.024

Li, M.Y., Zou, X.H., Niu, Y.G., Wang, W., and Liu, J.Z. (2018). Improving wind power utilization in system dispatch considering output and ramp rate dependent generator costs. Journal of Environmental Informatics, 32(1), 25-35. https://doi.org/10.3808 /jei.201800395

Li, W., Bao, Z., Huang, G.H., and Xie, Y.L. (2018). An inexact credibility chance-constrained integer programming for greenhouse gas mitigation management in regional electric power system under uncertainty. Journal of Environmental Informatics, 31(2), 111-122. https://doi.org/10.3808/jei.201500326

Li, Y.P., Huang, G.H., and Nie, S.L. (2007). Mixed interval-fuzzy twostage integer programming and its application to flood-diversion planning. Engineering Optimization, 39(2), 163-183. https://doi.org /10.1080/03052150601044831

Liu, L.R., Huang, C.Z., Huang, G.H., Baetz, B., and Pittendrigh, S.M. (2018a). How a carbon tax will affect an emission-intensive economy: A case study of the Province of Saskatchewan, Canada. Energy, 159, 817-826. https://doi.org/10.1016/j.energy.2018.06. 163

Liu, L.R., Huang, G.H., Baetz, B., Huang, C.Z., and Zhang, K.Q. (2019). Integrated GHG emissions and emission relationships analysis through a disaggregated ecologically-extended input-output model; A case study for Saskatchewan, Canada. Renewable and Sustainable Energy Reviews, 106, 97-109. https://doi.org/10.1016/j. rser.2019.03.001

Liu, L.R., Huang, G.H., Baetz, B., and Zhang, K.Q. (2018b). Environmentally-extended input-output simulation for analyzing production-based and consumption-based industrial greenhouse gas mitigation policies. Applied Energy, 232, 69-78. https://doi.org/10.1016 /j.apenergy.2018.09.192

Liu, S.M., Bi, T.S., Xue, A.C., and Liu, J.Z. (2018c). Equivalent model for calculating fault current from inverter-interfaced renewable energy generators. Journal of Environmental Informatics, 32(1), 3644. https://doi.org/10.3808/jei.201800392

Mirasgedis, S., Tourkolias, C., Tzovla, E., and Diakoulaki, D. (2014). Valuing the visual impact of wind farms: An application in South Evia, Greece. Renewable and Sustainable Energy Reviews, 39, 296311. https://doi.org/10.1016/j.rser.2014.07.100

Nguyen, K.Q. (2007). Wind energy in Vietnam: Resource assessment, development status and future implications. Energy Policy, 35(2), 1405-1413. https://doi.org/10.1016/j.enpol.2006.04.011 
Ren, G.R., Liu, J.F., Wan, J., Guo, Y.F., Hu, Q.H., and Yu, D.R. (2018). Prediction of the standard deviation of wind speed turbulence. Journal of Environmental Informatics, 32(1), 1-13. https://doi.org /10.3808/jei.201800389

Sliz-Szkliniarz, B. and Vogt, J. (2011). GIS-based approach for the evaluation of wind energy potential: A case study for the KujawskoPomorskie Voivodeship. Renewable and Sustainable Energy Reviews, 15(3), 1696-1707. https://doi.org/10.1016/j.rser. 2010.11.045

Son, E., Kim, H., Kim, H., Choi, W., and Lee, S. (2010). Integrated numerical method for the prediction of wind turbine noise and the long range propagation. Current Applied Physics, 10(2), S316-S319. https://doi.org/10.1016/j.cap.2009.11.034

United Nations Framework Convention on Climate Change. (2015). Canada's INDC Submission to the UNFCCC.

Van Haaren, R. and Fthenakis, V. (2011). GIS-based wind farm site selection using spatial multi-criteria analysis (SMCA): Evaluating the case for New York State. Renewable and Sustainable Energy Reviews, 15(7), 3332-3340. https://doi.org/10.1016/j.rser.2011.04. 010

Van Hoesen, J. and Letendre, S. (2010). Evaluating potential renewable energy resources in Poultney, Vermont: A GIS-based approach to supporting rural community energy planning. Renewable Energy, 35(9), 2114-2122. https://doi.org/10.1016/j. renene.2010.01.018

Voivontas, D., Assimacopoulos, D., Mourelatos, A., and Corominas, J. (1998). Evaluation of renewable energy potential using a GIS decision support system. Renewable Energy, 13(3), 333-344. https:// doi.org/10.1016/S0960-1481(98)00006-8

Yu, L., Li, Y.P., and Huang, G.H. (2019). Planning municipal-scale mixed energy system for stimulating renewable energy under multiple uncertainties-The City of Qingdao in Shandong Province, China. Energy, 166, 1120-1133. https://doi.org/10.1016/j.energy. 2018.10.157 